\title{
Organizational Contributions to Healthcare Worker (HCW) Burnout and Workplace Violence (WPV) Overlap: Is This an Opportunity to Sustain Prevention of Both?
}

\author{
Michael R. Privitera \\ University of Rochester Medical Center, Rochester, NY, USA \\ Email: michael_privitera@urmc.rochester.edu \\ Received 12 February 2016; accepted 12 April 2016; published 15 April 2016 \\ Copyright (C) 2016 by author and Scientific Research Publishing Inc. \\ This work is licensed under the Creative Commons Attribution International License (CC BY). \\ http://creativecommons.org/licenses/by/4.0/ \\ (c) (i) Open Access
}

\begin{abstract}
The effects of Burnout in healthcare workers (HCW) are experienced by the worker, other staff, the institution and patients under their care on a daily basis. Workplace violence (WPV) has a spectrum of forms. In more extreme forms it generally is low frequency but has high impact when it occurs. Healthcare systems' efforts to reduce Burnout are more likely to remain sustained since the impact is experienced daily and awareness is increasingly publicized. The efforts to reduce WPV are harder to sustain due to the lower frequency combined with daily competing administrative demands despite best intentions. Could efforts to reduce the overlapping organizational contributions to both HCW Burnout and WPV be a strategy to sustain prevention of WPV while preventing Burnout? A model of overlapping organizational contributions to HCW Burnout and WPV is built from supporting literature. Recommendations are made for leadership and management style interventions. Potential benefits would be higher quality and satisfaction in patient care by means of higher satisfaction in the delivery of care, recruitment and retention of excellent staff, retention of high quality institutional knowledge and reputation.
\end{abstract}

\section{Keywords}

Burnout, Healthcare Systems, Organizational Contributions, Workplace Violence

\section{Introduction}

Efforts to sustain WPV prevention frequently get derailed despite how WPV affects individuals, systems and

How to cite this paper: Privitera, M.R. (2016) Organizational Contributions to Healthcare Worker (HCW) Burnout and Workplace Violence (WPV) Overlap: Is This an Opportunity to Sustain Prevention of Both? Health, 8, 531-537. 
quality and safety of patient care [1]. Many "mainstream medicine" competing demands occur in running a healthcare system, and WPV prevention often falls from the high priority status that it has after a violent event occurs. This priority loss occurs despite the best intentions of caring administrators and clinicians. Organizational contributions to WPV are frequently not recognized and are missing in Occupational Safety and Health Administration [2] WPV Typology. Organizational contributions to WPV are usefully clarified in Bowie Expansion of WPV Typology [3]. WPV has a spectrum of forms [4]. In more extreme forms, it is generally low frequency but high impact.

HCW Burnout for decades had been relegated to the individual worker to solve. Now, extensive research demonstrates that HCW Burnout is currently experienced daily by a high percentage of HCWs and affects the individual, other staff, the institution and the patients under their care [5].

There is a large overlap of organizational contributions to Burnout and WPV (see Figure 1).

Healthcare system awareness of the many devastating effects that HCW Burnout is a newly emerging area, and increasing efforts are being suggested to try to prevent and mitigate Burnout [6] [7]. Could efforts to reduce overlapping organizational contributions to both Burnout and WPV be a missing strategy that may be able to sustain prevention of both?

\section{Burnout}

The National Institute for Occupational Safety and Health defines occupational stress as "the harmful physical and emotional responses that occur when the requirements of the job do not match the capabilities, resources, or needs of the worker" [8]. Professional Burnout is one of the outcomes of chronic high level occupational stress.

Although the stressors that contribute to Burnout differ by profession, the human reaction of Burnout is similar. Burnout is manifested by: Exhaustion despite rest, Depersonalization with cynicism, sarcasm, keeping patients at a distance to not drain you more, compassion fatigue with nothing left to give. Lack of Efficacy from questioning the use of the work, to work becoming subpar [9].

The causes of Burnout are multifactorial and include the intrinsic work and training of being a HCW, certain categories of modifiable work stress, and personal life issues. No central agency or administrative body defines what the total reasonable job description is for the HCW. Incrementalism has occurred over the years with

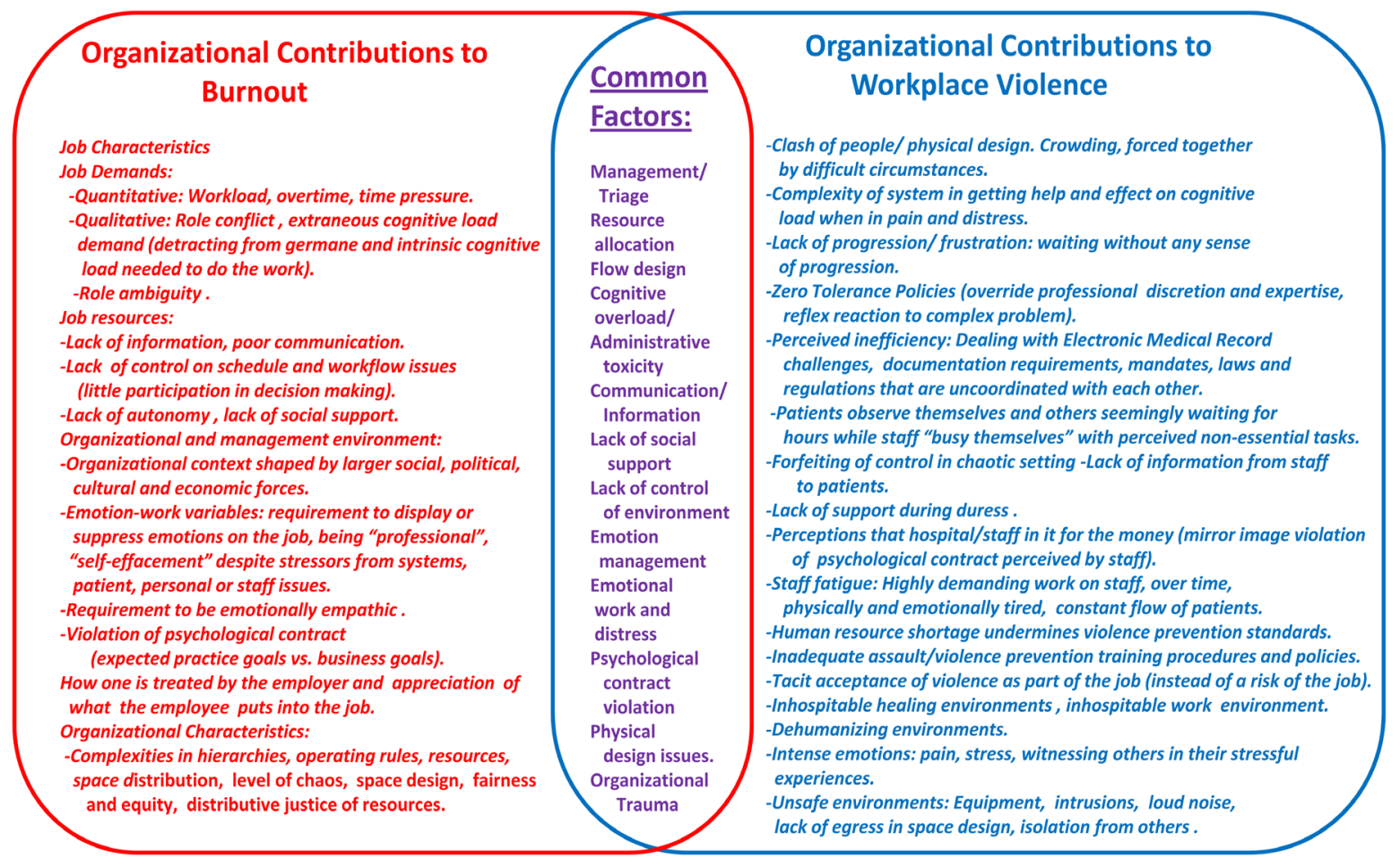

Figure 1. Common factors: organizational contributions to burnout and workplace violence. 
HCWs having to accept increased expectations, regulations and mandates from state and national authorities as well as payers. There is increasing loss of HCW control of their workflow made by near and distant sources diminishing the time available to see and relate to patients under their responsibility. HCWs went through considerable personal and financial sacrifices of training for their advanced degrees with the objective of meaningfully improving the lives of patients. The more that this objective is thwarted by activity that is not felt to be meaningfully related, the more the risk of Burnout in this group [10].

The modifiable stressors at work are categorized as emotional, cognitive or physical excessive workload, lack of control, poor balance between reward and effort, lack of community, lack of fairness, and value conflicts/ moral distress arising from prescribed work environment [11]. Cognitive load theory posits three types of cognitive load: intrinsic-inherent to problem to be solved, germane-associated with and necessary part of the problem solving and extraneous-that portion of cognitive load that reduces neural resources to process intrinsic and germane load, but can be lessened by better design [12]. Reducing extraneous cognitive load can be a key component for reducing overall cognitive load on the individual.

HCWs are particularly vulnerable to Burnout due to "hidden curriculum" in training of self-effacement: How tired you feel is not important and needs to be suppressed, the patient is always first [13]. Until the last few decades this culture, though inherently difficult to maintain, was mostly in the autonomous realm of personal choice. In a setting of heavy influence of the business of medicine, governmental and other authoritative mandates that are expanding administrative requirements in healthcare the unharmonized and non-coordinated fashion of the sum total may not be humanly possible to achieve-hence unwittingly has human cost. The HCW and their administrative leadership often lose awareness of how stressed the individual really is. There are internal and sociopolitical cultural forces that cause perpetuation of old expectations despite the new healthcare environment. Research is suggesting that in our high chronic stress environments a rigidly applied self-effacement philosophy is not safest for the individual or the patient [14]. There is a balance between self-effacement and self-care that should be encouraged and achieved for a sustainable high quality healthcare workforce.

\section{Burnout Impact Factors}

High Burnout is associated with a higher personal healthcare expenditure per person compared with low Burnout HCWs [15]. Patients of healthcare workers with high-exhaustion and high depersonalization had significantly lower patient satisfaction scores, compared to patients of those with low-exhaustion and low-depersonalization, respectively [16]. Burnout is associated with increased rates of medical errors, malpractice risk, HCW turnover, and increased startup and ramp up costs [17]. Systemically-induced problems with cognitive performance of the provider or staff can occur, especially if adverse conditions persist and no clear end-point to the stressful circumstances exist [18]. Chronic high level of stress has sustained secretion of norepinephrine and later cortisol at high levels [19] [20]. Anatomical changes to the brain occur from release of the enzyme protein kinase $\mathrm{C}$ signaled by the amygdala breaking down the dendritic spines of the neurons in the pre-frontal cortex which controls executive function [21]. Executive function controls the ability to focus, keep attention, selfcontrol of behavior and speech, planning, organizing, perspective taking, cognitive flexibility, medical and other decision making, ability to defer gratification, estimating time and working memory [22]. Healthcare workforce, the healthcare institutions, and the patient public are at increasing physical, emotional, and financial risk by means of unaddressed Burnout of HCWs [14] [23]-[25].

The personal toll of Burnout in HCW is lower levels of interest in engaging with others in normal activities, higher levels of divorce, alcohol and drug addiction, suicide, conflicts at home, difficulty sleeping, coronary heart disease increase 1.4 fold, up to 1.79 at high Burnout levels, and visits to primary care provider double the medical cost expenditure [26]. High Burnout also increases the risk of being a victim of WPV [27]. Addressing the impact of occupational stress and/or burnout on providers is a business imperative that warrants attention [28].

\section{Workplace Violence}

Workplace violence has a broad spectrum of behaviors in the definition by National Institute of Occupational Safety and Health (NIOSH) which is a division of the Centers for Disease Control [8]. Any physical assault, threatening behavior, or verbal abuse occurring in the workplace, includes but is not limited to such events as beatings, shootings, rape, suicide or attempts psychological traumas, such as threats to harm, obscene phone 
calls, intimidation, bullying, incivility, harassment, including being followed or sworn at. The examples in italics tend to also be labeled as disruptive behavior. Healthcare systems have been mandated to reduce disruptive behavior by The Joint Commission, since they lead to poor quality and safety of care [29].

Understanding that incivility, disruptive behavior and other workplace violence are responses to stressors that may be internal, external of both is key to preventing and mitigating these violent responses [30]. It must not be just "bad apples" (prone individuals) that concern us, but the possibility of a "bad barrel" (organizational contributions to violence) should be considered [31].

\section{Workplace Violence Impact Factors}

Effects of WPV on quality and safety of care have been mentioned. Individual staff exposed to WPV are biologically and psychologically not the same, with risk of physical and psychological symptoms as a result. It is estimated that $10 \%$ of staff so exposed experience Posttraumatic Stress Disorder (PTSD) [1] [32] [33].

Institutional tolls of WPV include problems with staff commitment, morale, engagement, increased insurance and worker's compensation costs, quality of patient care, turnover, sick leave, presenteeism, poor productivity and Burnout [1]. Avoidance of people and patients, somatic symptoms Depression, PTSD and stress related disorders can occur in the individual [29].

\section{Discussion}

Review of the literature shows directional relationships and a vicious cycle model can be built. Organizational factors contribute to Burnout, Burnout can contribute to WPV, organizational factors contribute to WPV, and then WPV can contribute to Burnout (see Figure 2). Hence, by focusing on the overlapping factors in organizational contributions to Burnout and WPV, an informed strategy emerges. Suggested interventions for healthcare systems to interrupt this cycle and reduce the organizational contributions to Burnout and WPV are outlined in Table 1.

\section{Conclusions}

Healthcare worker Burnout and workplace violence in healthcare are complex issues that have an array of causes and effects. Identifying and intervening in the overlapping contributions to both HCW Burnout and WPV hold promise in being able to reduce both. HCW career satisfaction is highly correlated with patient health care satisfaction [36], which is well articulated by adopting the Quadruple Aim in healthcare: improving patient experience of care, quality of care, reduced costs, and improving the experience of providing care [37].

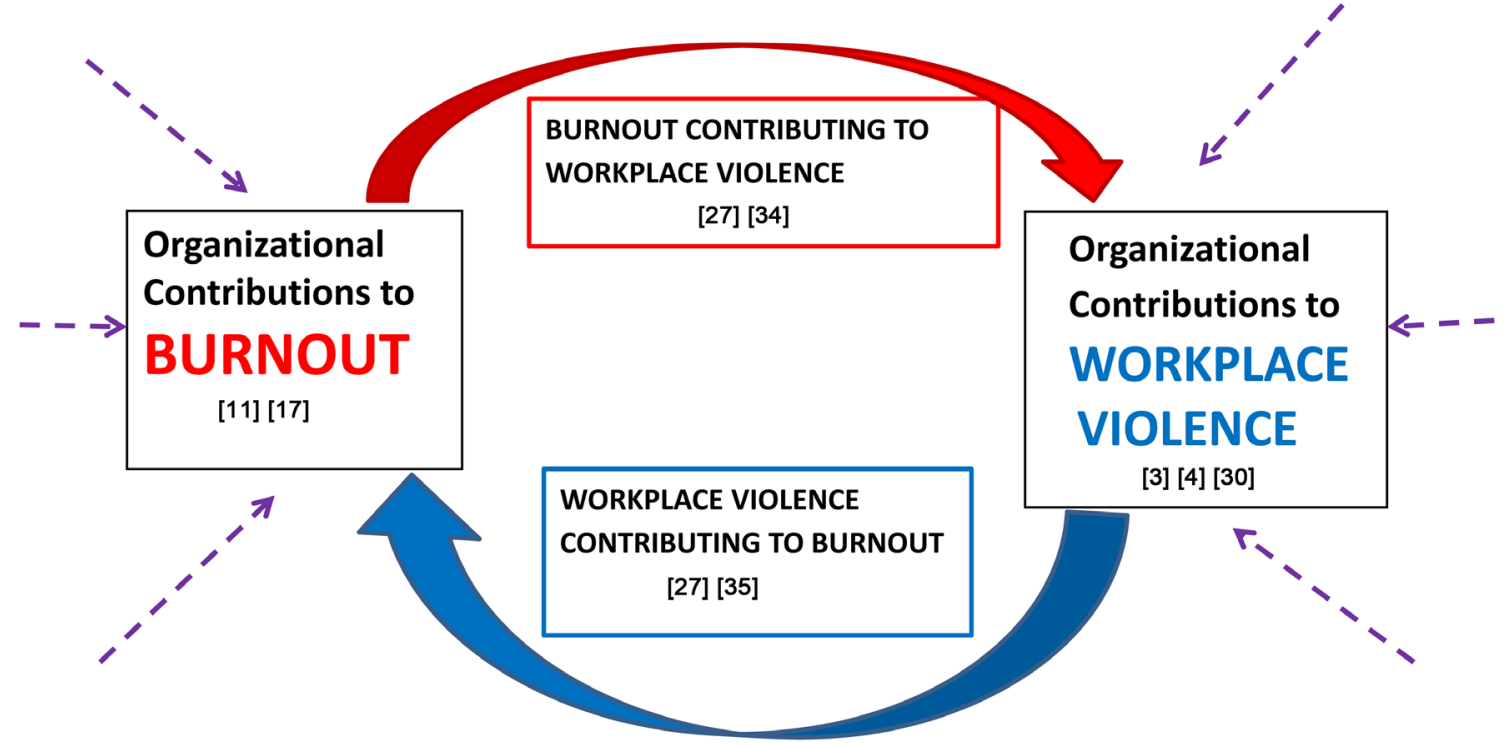

Figure 2. Vicious cycle of burnout and workplace violence. 
Table 1. Healthcare system interventions to reduce organizational contributions to both Burnout and WPV.

- Management and Triage-reduce disruptive or inefficient work flows and preserving self-esteem in ways possible for HCWs and patients. This might be achieved by policy, workflow design, and sufficient support staff. Resource allocation with these concepts in mind.

- Logistical solutions to handle the multiple mandatory and regulatory expectations of HCWs can be offered at institutional level. Assisting the HCWs with compliance helps the healthcare system become compliant and efficient as a whole.

- Flow design of the physical workspace to reduce interruptions, barriers to physical care of patients and improve safety. Need rank-and-file HCW (those closest to the problem) input on designs.

- Reducing extraneous cognitive load and administrative toxicity — can the organization take on efforts to apply cognitive ergonomic principles? Use these human factor principles that apply to best use of HCW fund-of-knowledge and decision-making capabilities. Work strategies that are in alignment with best mental function will have better efficiencies and subsequently less stress.

- Communication methods to be enhanced between administration, HCWs and patients.

- Social and instrumental support of HCWs during crises and bad outcomes.

- Allowing HCWs increase decisional control of their practice environment. Sometimes suggestions need to be anonymous to break the silence of staff worried about repercussions on their career.

- Emotion management interventions-resources and education to assist emotion management to be provided.

- Emotional work in dealing with patient distress needs to be recognized and accounted for as part of the efforts put forth by HCWs.

- Psychological contract violation (e.g. of respect, empathy, trust, fairness, expected practice goals vs. expected business goals, etc.). and the perceptions thereof need to be addressed and mitigated for HCWs while still living in the world of the business of medicine.

- Organizational trauma (OT), like mergers and acquisitions, downsizing, threats of downsizing and other such history should be acknowledged and factored in as the organization and its employees attempt to be resilient and move forward. This takes recognition of how OT affects the workers sense of security, self-worth, health, well-being and consequently engagement.

OSHA guidelines mandate providing employees a place of employment free of recognized hazards [2]. Patient safety and employee safety are inextricably linked. The more we recognize and address overlapping root causes of Burnout and WPV, the more effective and long lasting our interventions could be.

\section{References}

[1] Privitera, M. and Arnetz, J (2011) Effect of Workplace Violence on Staff, Institution, and Quality of Patient Care. In: Privitera, M.R., Ed., Workplace Violence in Mental and General Healthcare Settings, Jones and Bartlett Publishers, Sudbury, 29-42.

[2] Occupational Safety and Health Administration (OSHA) General Duty Clause. Section, 5(a)(1). https://www.osha.gov/law-regs.html

[3] Bowie, V. (2011) An Emerging Awareness of the Role Organizational Culture and Management Style Can Plan in Triggering Workplace Violence. In: .Privitera, M.R., Ed., Workplace Violence in Mental and General Healthcare Settings, Jones and Bartlett Publishers, Sudbury, 43-58.

[4] Privitera, M.R., Bowie, V. and Bowen, B. (2015) Translational Models of Workplace Violence in Health Care. Violence and Victims, 30, 293-307.

[5] Lin, Y.-W. (2013) The Causes, Consequences, and Mediating Effects of Job Burnout Among Hospital Employees in Taiwan. Journal of Hospital Administration, 2, 15-27.

[6] Rosenstein, A. (2012) Physician Stress and Burnout: What Can We Do? American College of Physician Executives, 38, 22-30.

[7] Privitera, M.R., Bowie, V. and Bowen, B. (2014) Overlapping Organizational Contributions to Workplace Violence (WPV) and Workforce Burnout in Healthcare: Is Reduction of Burnout and Opportunity to Reduce Both? In: Needham, I., Kingma, M., et al., Eds., 4th International Conference on Violence in the Health Sector. Towards Safety, Security, and Wellbeing for All, Kavana, 22-24 October 2014, 183-184.

[8] Department of Health and Human Services, Centers for Disease Control and Prevention (2008) National Institute for Occupational Safety and Health. Exposure to Stress. Occupational Hazards in Hospitals. http://www.cdc.gov/niosh/docs/2008-136/pdfs/2008-136.pdf

[9] Maslach, C., Schaufeli, W.B. and Leiter, M.P. (2001) Job Burnout. Annual Review of Psychology, 52, 397-422. http://dx.doi.org/10.1146/annurev.psych.52.1.397

[10] Shanafelt, T., West, C., et al. (2009) Career Fit and Burnout among Academic Faculty. Archives of Internal Medicine, 169, 990-995. http://dx.doi.org/10.1001/archinternmed.2009.70

[11] Maslach, C. and Leiter, M.P. (1997) The Truth About Burnout. How Organizations Cause Personal Stress and What To Do About It. Jossey-Bass Publishers, San Francisco.

[12] Sweller, J. (1994) Cognitive Load Theory, Learning Difficulty and Instructional Design. Learning and Instruction, 4, 
295-312. http://dx.doi.org/10.1016/0959-4752(94)90003-5

[13] Hafferty, F.W. and Franks, R. (1994) The Hidden Curriculum, Ethics Teaching, and The Structure of Medical Education. Academic Medicine, 69, 861-871. http://dx.doi.org/10.1097/00001888-199411000-00001

[14] Bloom, S.L. and Farragher, B. (2011) I Gotta Get Out of This Place: Workplace Stress as a Threat to Public Health. In: Bloom, S.L. and Farragher, B., Eds., Destroying Sanctuary. The Crisis in Human Service Delivery Systems, Oxford University Press, New York, 61-90.

[15] de Beer, L., Pienaar, J. and Rothmann, S. ( 2013) Linking Employee Burnout to Medical Aid Provider Expenditure. South African Medical Journal, 103, 89-93. http://dx.doi.org/10.7196/samj.6060

[16] Anagnostopoulos, F., Liolios, E., Persefonis, G., Slater, J., Kafetsios, K. and Niakas, D. (2012) Physician Burnout and Patient Satisfaction with Consultation in Primary Health Care Settings: Evidence of Relationships from a One-withMany Design. Journal of Clinical Psychology in Medical Settings, 19, 401-410. http://dx.doi.org/10.1007/s10880-011-9278-8

[17] Privitera, M.R., Rosenstein, A.H., Plessow, F. and LoCastro, T.M. (2015) Physician Burnout and Occupational Stress: An Inconvenient Truth with Unintended Consequences. Journal of Hospital Administration, 4, 1-8.

[18] Arnsten, A.F.T. (2009) Stress Signaling Pathways That Impair Prefrontal Cortex Structure and Function. Nature, 10, 410-422.

[19] Liston, C., McEwen, B.S. and Casey, B.J. (2009) Psychosocial Stress Reversibly Disrupts Prefrontal Processing and Attentional Control. Proceedings of the National Academy of Sciences, 106, 921-917. http://dx.doi.org/10.1073/pnas.0807041106

[20] Plessow, F., Kiesel, A. and Kirschbaum, C. (2012) The Stressed Prefrontal Cortex and Goal-Directed Behavior: Acute Psychosocial Stress Impairs the Flexible Implementation of Task Goals. Experimental Brain Research, 216, 397-408. http://dx.doi.org/10.1007/s00221-011-2943-1

[21] Savic, I. (2013) Structural Changes of the Brain in Relation to Occupational Stress. Cerebral Cortex, 25, $1554-1564$. http://dx.doi.org/10.1093/cercor/bht348

[22] Leh, S.E., Petrides, M. and Strafella, A.P. (2010) The Neural Circuity of Executive Functions in Healthy Subjects and Parkinson's Disease. Neuropsychopharmacology, 35, 70-85. http://dx.doi.org/10.1038/npp.2009.88

[23] Zapf, D., Seifert, C., Schmuttee, B., Mertini, H. and Holtz, M. (2001) Emotion Work and Job Stressors and Their Effects On Burnout. Psychology and Health, 16, 527-545. http://dx.doi.org/10.1080/08870440108405525

[24] Arnsten, A.F.T. (1998) The Biology of Being Frazzled. Science, 280, 1711-1712.

[25] Privitera, M.R., Plessow, F. and Rosenstein, A.H. (2015) Burnout as a Safety Issue: How Physician Cognitive Workload Impacts Care. National Patient Safety Foundation e-News.

http://npsf.site-ym.com/blogpost/1158873/224974/Burnout-as-a-Safety-Issue--How-Physician-Cognitive-Workload-Im pacts-Care

[26] Toker, S., Melamed, S., Berliner, S., Zeltser, D. and Shapira, I. (2012) Burnout and Risk of Coronary Heart Disease: A Prospective Study of 8838 Employees. Psychosomatic Medicine, 74, 840-847. http://dx.doi.org/10.1097/PSY.0b013e31826c3174

[27] DiMartino, V. (2003) Relationship of Work Stress and Workplace Violence in the Health Sector. Joint Programme on Workplace Violence in the Health Sector. http://www.conflictprofessional.com/admin/resourcecentre/docs/Di\%20Martino\%20WPV\%20StressViolence.pdf

[28] Burton, J., Industrial Accident Prevention Association (2008) The Business Case for a Healthy Workplace. https://www.uml.edu/docs/fd_business_case_healthy_workplace_tcm18-42671.pdf

[29] The Joint Commission. Sentinel Event Alert (2008) Behaviors That Undermine a Culture of Safety. Issue 40. http://www.jointcommission.org/assets/1/18/sea_40.pdf

[30] Bowen, B., Privitera, M.R. and Bowie, V. (2011) Reducing Workplace Violence by Creating Healthy Workplace Environments. Journal of Aggression Conflict and Peace Research, 3, 185-198. http://dx.doi.org/10.1108/17596591111187710

[31] O’Boyle, E.H., Forsyth, D.R. and O’Boyle, A.S. (2011) Bad Apples or Bad Barrels: An Examination of Group-and Organizational-Level Effects in the Study of Counterproductive Behavior. Group \& Organization Management, 36, 39-69. http://dx.doi.org/10.1177/1059601110390998

[32] Findorff, M.J., McGovern, P.M. and Sinclair, S. (2005) Work-Related Violence Policy: A Process Evaluation. $A A O H N$ Journal, 53, 360-369.

[33] Caldwell, M.F. (1992) Incidence of PTSD among Staff Victims of Patient Violence. Hospital \& Community Psychiatry, 4, 838-839. http://dx.doi.org/10.1176/ps.43.8.838 
[34] Chen, P.Y. and Spector, P.E. (1991) Relationships of Work Stressors With Aggression, Withdrawal, Theft and Substance Abuse: An Exploratory Study. Journal of Occupational and Organizational Psychology, 65, 177-184. http://dx.doi.org/10.1111/j.2044-8325.1992.tb00495.x

[35] Estryn-Behar, M., van der Heijden, B., et al. (2008) The NEXT Study Group. Violence Risks in Nursing—Results from the European “NEXT” Study. Occupational Medicine, 58, 107-114. http://dx.doi.org/10.1093/occmed/kqm142

[36] DeVoe, J., Fryer Jr., G.E., Straub, A., McCann, J. and Fairbrother, G. (2007) Congruent Satisfaction: Is There Geographic Correlation between Patient and Physician Satisfaction? Medical Care, 45, 88-94. http://dx.doi.org/10.1097/01.mlr.0000241048.85215.8b

[37] Sikka, R., Morath, J.M. and Leape, L. (2015) The Quadruple Aim: Care, Health, Cost and Meaning in Work. BMJ Quality and Safety, 24, 608-610. http://dx.doi.org/10.1136/bmjqs-2015-004160 